\title{
Intrusion and Lateral Luxation of Permanent Incisors in Pediatric Patient Secondary to Dental Trauma: Case Report
}

\author{
Katherine B Jones ${ }^{1 *}$, Ann Greenwell ${ }^{2}$ and James E Jones ${ }^{1}$ \\ ${ }^{1}$ Department of Pediatric Dentistry, Indiana University School of Dentistry, USA \\ ${ }^{2}$ Department of Pediatric Dentistry, University of Louisville School of Dentistry, USA
}

Submission: February 03, 2016; Published: March 01, 2017

*Corresponding author: Katherine B Jones, MD, MSD, Clinical Assistant Professor of Pediatric Dentistry, Indiana University School of Dentistry, Riley Hospital for Children, 705 Riley Hospital Drive, Suite 4205, Indianapolis, Indiana 46202-5200 USA, Tel: 317-944-9604; Fax: 317-948-0760; Email: jej7@iu.edu

\begin{abstract}
Intrusion injuries, though considered rare in permanent dentition, are seen more frequently in pediatric patients. This case involved an11year-old male who severely intruded and luxated teeth \#7 and \#8. The aim of this case report is to review protocols taken to treat this severe dental trauma and to improve procedures for severe traumas in the future. Throughout the four months the patient was in active treatment, his treatment involved various specialties. At the conclusion of treatment, the teeth were reposition back into the arch and restored to their original state through orthodontic movement. Overall, the treatment regime was deemed successful because the teeth were restored to their natural position in the dental arch. Knowing the reasoning for the treatment protocol for these injuries enhances the best prognosis for the patient experiencing this difficult clinical presentation.
\end{abstract}

Keywords: Intrusion; Luxation; Incisors; Permanent; Trauma

Abbreviation: TJ: Thetempomandibular Joint

\section{Introduction}

Traumatic dental injuries are common among pediatric dental patients. Approximately $20-30 \%$ of children have suffered dental injuries by the age of 12 [1]. Intrusion injuries, though considered rare in the permanent dentition [2], are seen more frequently in the pediatric population [3]. Intrusion is defined as a displacement of the tooth axially into the alveolar socket. Accompanied by a lateral luxation, there could be a communication or fracture of the alveolar socket [1]. This type of injury is considered severe because of severance of the neurovascular pulp supply, entrapment of the tooth in broken bone, displacement of the marginal seal and compression of the periodontal ligament $[1,3,4]$.

Three different treatment modalities are considered for luxation/intrusion injuries: expected spontaneous re-eruption, surgical repositioning, or orthodontic movement [1-4]. The patients' age, stage of root development, and severity of intrusion must be taken into consideration when determining definitive treatment $[1,3]$. There is a lack of consensus if spontaneous reeruption is effective in permanent dentition therefore it is not typically used unless it is an immature permanent tooth $[2,3]$. Surgical repositioning consists of using forceps to return the tooth to its natural position followed by splinting. Orthodontic repositioning uses bands, brackets, and wire to reposition the teeth over a period of weeks. In most cases this treatment begins a few days after trauma because of bleeding and initial swelling [3]. This case report demonstrates the treatment management of a traumatically intruded and luxated central and lateral incisor (teeth \#7 and \#8) by orthodontic movement over a four-month period.

\section{Case Report}

An 11-year-old male reported to Kosair Children's Hospital on for severe dental trauma. Trauma occurred when the patient collided with a tree while riding his bike. The metal bike frame hit patient's lower face causing intrusion and luxation of anterior teeth. The patient was wearing a helmet and no significant head injury was reported. The patient had an essentially negative medical history. 
The patient suffered lacerations to the lower lip and chin requiring sutures. The tempomandibular Joint (TMJ) was evaluated for trauma with exam and radiographs and was found to be within normal limits. Intraorally, teeth \#7 and \#8 were intruded $5 \mathrm{~mm}$ and luxated 3-4 mm. cortical plate fracture was noted on the lingual of teeth \#7 and \#8 (Figure 1). Teeth \#23 through 26 were subluxated with slight Class 1 mobility. Teeth \#8, \#24 and \#22 exhibited an uncomplicated fracture.

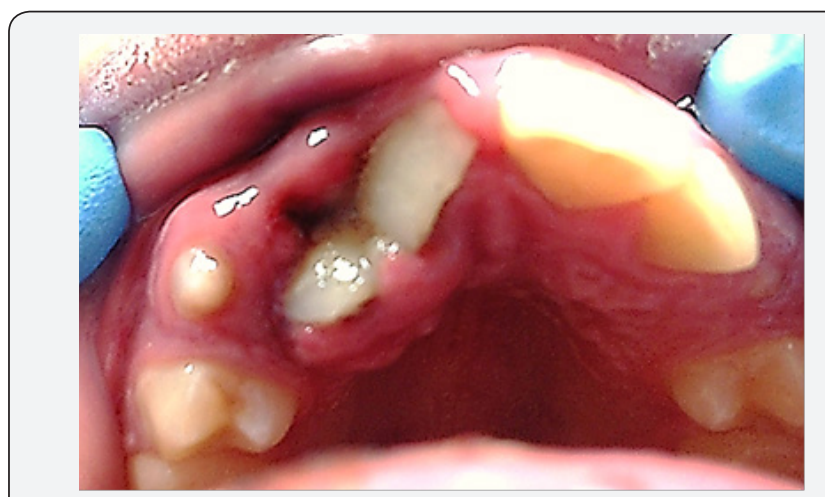

Figure 1: Intraoral Clinical view 5 days after trauma.

The patient was sedated due to intense fear and anxiety. Lacerations of the lower lip and chin were sutured. Local anesthesia was given in the area of teeth \#7 and \#8 [2\% Lidocaine with 1:100,000 epinephrine, $1.7 \mathrm{cc}$ ). Using digital palpation, teeth were attempted to be repositioned with no success. The patient was placed on a 10-day regimen of oral antibiotics. Parents were instructed to follow up with the University of Louisville Pediatric Dentistry Department for further treatment options.

Consults were obtained from the University of Louisville School Of Dentistry Departments of Endodontics, Orthodontics and Oral and Maxillofacial Surgery. It was determined that orthodontic extrusion would be the best treatment option in that surgical replacement is only possible 2 hours post trauma. The Endodontist suggested re-evaluate teeth \#7 and \#8 in 10 days to allow for healing, but endodontic would need to be performed as soon as extrusion could be achieved for proper canal access. The patient was instructed to remain on a soft diet for one week.

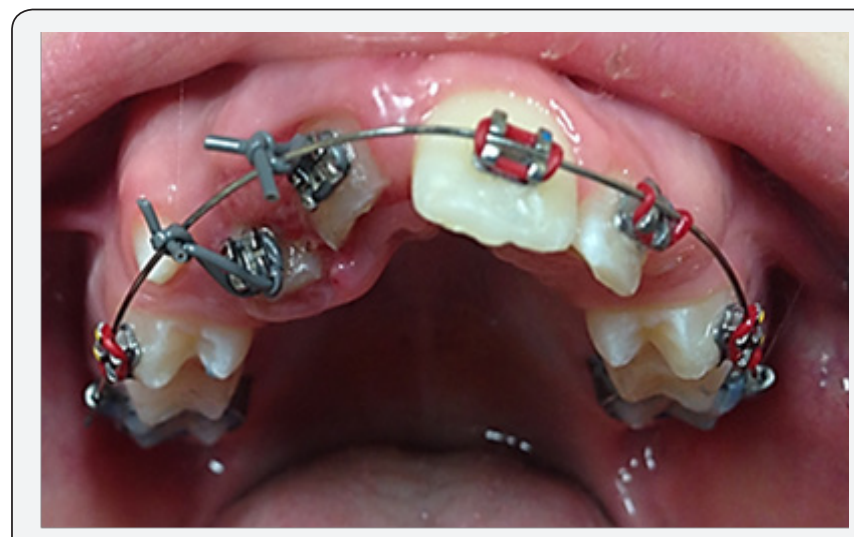

Figure 2: Bracketing 2 weeks post trauma.
Initial bracketing was performed two weeks following trauma (Figure 2). Bands were placed on maxillary first permanent molars and teeth 5, 6, 9, 10, 12 were bracketed. This allowed for maximum anchorage. Unitek 3M Nitinol Class 0.016 inch wire was placed into the brackets and ligated with rubber bands for anchorage. A ligature wire was placed around the brackets and tied onto the wire to initiate bodily movement of teeth \#7 and \#8. The patient was placed on a two week evaluation to ensure that orthodontic movement was progressing and teeth could be monitored for potential signs of necrosis, ankyloses,internal or external root resorption. At every observation appointment the patient's orthodontic progression was examined.

Five weeks post-trauma, adequate tooth movement was achieved such that initial endodontic therapy was performed on teeth \#7 and \#8. Canals were cleaned and shaped using Protaper and Vortex files. $\mathrm{NaOCl}$ and EDTA were used to irrigate canals. Canals were dried with paper points, $\mathrm{CaOH}$, cotton pellet and IRM was placed. The treatment was completed four weeks later and canals were filled with gutta percha (Figure 3). After 4 months of orthodontic treatment the teeth were realigned in the arch (Figure 4 \& 5). The patient was dismissed to return to private pediatric dentist for continuation of care.

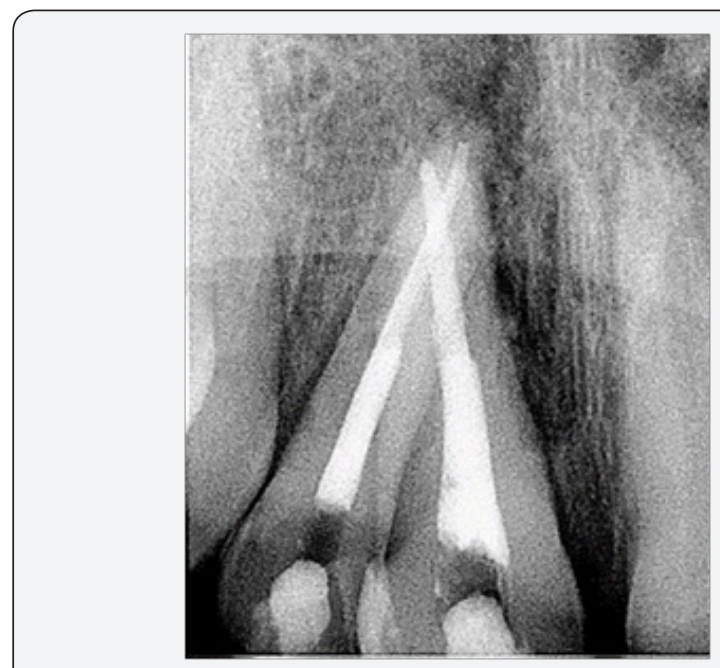

Figure 3: Completed root canals teeth \#7 and \#8.

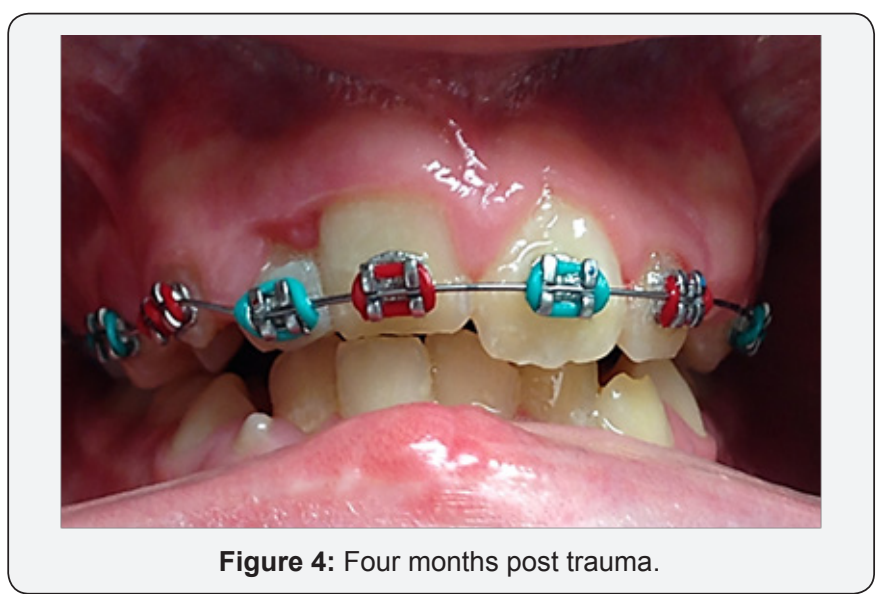




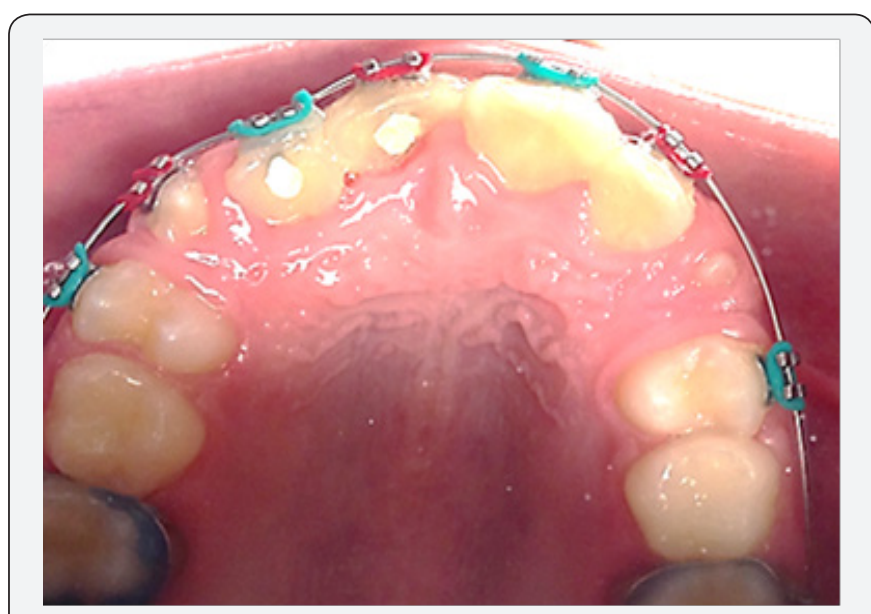

Figure 5: Four months post trauma.

\section{Discussion}

Orthodontic movement was determined to be the treatment of choice for this case.

Providers considered the patients age, extent of root development and extent of intrusion. The patient was a healthy 11-year-old male. The apices of teeth \#7 and \#8 had not fully closed apex and the amount of intrusion was approximately $5 \mathrm{~mm}$. According to Andreasen, orthodontic movement is considered the treatment of choice in this situation [1]. Adolescent bone is less mineralized and has a higher resilience [5] which practitioners could take advantage of the slow movement of teeth over a period of weeks. This treatment modality reduces the possibility of root resorption; which approximately occurs in $40 \%$ of cases $[6,7]$.

Luxation injuries can cause crushing of PDL fibers and vasculature that is essential to keep pulpal vitality. Andreasen states there is a $90 \%$ chance of pulpal necrosis with a $5 \mathrm{~mm}$ intrusion injury [6]. Typically, unsuccessful pulp healing is evident radiographically 2-4 weeks after trauma [1]. Endodontic therapy can prevent pulpal necrosis and is typically recommended within 3-4 weeks post trauma [1]. In this case, endodontic treatment was not started till 5 weeks post trauma due to the severity of intrusion and lack of adequate orthodontic movement to achieve access to canals.

The patient was placed on frequent recalls where teeth were examined intraorally and with radiographic evaluation. The longtermprognosis of these teeth is guarded. Ankylosis and tooth loss must be considered in cases of severe trauma. Ankylosis can be caused through inflammatory-mediated and mechanical alterations in the periodontal ligament as well as insufficient functional cellular elements survive to suppress osteogenic activity. This disruption allows growth of bone across the periodontal ligament $[1,8,9]$. This can eventually lead to the loss of the tooth. Over a ten-year period, ankylosis occurs in $15.9 \%$ of the cases, while tooth loss in about $6.9 \%$ of cases [10].
Patient education and compliance was extremely important in this case. Having the patient and parents understand the magnitude of treatment and why it is being performed was imperative. In this case, the patient compliance was good.

\section{Conclusion}

Traumatic dental injuries are prevalent among adolescents. In this case, orthodontic repositioning was determined the treatment of choice. The literature emphasizes that there is no optimal treatment for traumatically intruded permanent teeth [2,11-13]. It is important to be able to properly examine and evaluate these traumatic injuries. Knowing the treatment options and reasoning for the treatment protocol for these injuries will ensure the best prognosis for the patient experiencing this difficult traumatic event.

\section{Conflict of Intrest}

There was no financial interest or any conflict of interest with any of the authors of this case presentation.

\section{References}

1. Andreasen JO, Bakland LK, Flores MT, Andreasen FM, Andersson L (2003) Classification of dental injuries. In: Andreasen JO, Bakland LK, Flores MT, Andreasen FM, Andersson L (Eds.), Traumatic dental injuries - a manual. ( $2^{\text {nd }}$ edn), Wiley-Blackwell, Oxford, UK, p. 16-17.

2. Al-Badri S, Kinirons M, Cole B, Welbury R (2002) Factors Affecting Resorption In Traumatically Intruded Permanent Incisors In Children. Dent Traumatol 18(2): 73-76.

3. Andreasen JO, Bakland LK, Matras RC, Andreasen FM (2006) Traumatic Intrusion Of Permanent Teeth. Part 1. An Epidemiological Study Of 216 Intruded Permanent Teeth. Dent Traumatol 22(2): 83-89.

4. Neto, JJ, Gondim JO, de Carvalho FM, Giro EM (2009) Longitudinal Clinical And Radiographic Evaluation Of Severely Intruded Permanent Incisors In A Pediatric Population. Dent Traumatol 25(5): 510-514.

5. Lauridsen E, Hermann NV, Gerds TA, Kreiborg S, Andreasen JO (2012) Pattern of Traumatic Dental Injuries in the Permanent Dentition among Children, Adolescents, and Adults. Dent Traumatol 28(5): 358- 363.

6. Andreasen JO, Bakland LK, Andreasen FM (2006) Traumatic intrusion of permanent teeth. Part 2. A clinical study of the effect of preinjury and injury factors, such as sex, age, stage of root development, tooth location, and extent of injury including number of intruded teeth on 140 intruded permanent teeth Dent Traumatol 22(2): 90-98.

7. Dias RS, Cajazeira Neto JA, de Carvalho FM, Moreira Neto JJ (2009) Surgical Repositioning of a Traumatically Intruded Permanent Incisor in a Patient with Rheumatic Fever: Case Report. Dental Traumatol 25(1): e12-15.

8. Andreasen JO (1980) Analysis of Pathogenesis and Topography of Replacement Root Resorption (Ankylosis) after Replantation of Mature Permanent Incisors in Monkeys. Swed Dent J 4(6): 231-240.

9. Lekic P, Mc Culloch CA (1996) Periodontal Ligament Cell Populations: The Centralrole of Fibroblasts in Creating A Unique Tissue. Anat Rec 245(2): 327-341.

\section{0.http://dentaltraumaguide.org/}

11.Andreasen JO, Bakland LK, Andreasen FM (2006) Traumatic intrusion of permanent teeth. Part 3. A clinical study of the effect of treatment variables such as treatment delay, method of repositioning, type of splint, length of splinting and antibiotics on 140 teeth Dent Traumatol 22(2): 99-111. 
12.Calasans-Maia Jde A, Calasans-Maia MD, da Matta EN, Ruellas AC (2003) Orthodontic Movement In Traumatically Intruded Teeth: A Case Report. Dent Traumatol 19(5): 292-295.

This work is licensed under Creative Commons Attribution 4.0 Licens

DOI: 10.19080/ADOH.2017.04.5555628
13. Jones JE, Spolnik K, Yassen G (2015) Management of trauma to the teeth and supporting structures. Chapter 27, McDonald and Avery's Dentistry for the Child and Adolescent, C.V. Mosby Co., St., St. Louis, Missouri, pp. 563-602.

\section{Your next submission with Juniper Publishers will reach you the below assets}

- Quality Editorial service

- Swift Peer Review

- Reprints availability

- E-prints Service

- Manuscript Podcast for convenient understanding

- Global attainment for your research

- Manuscript accessibility in different formats

( Pdf, E-pub, Full Text, Audio)

- Unceasing customer service

Track the below URL for one-step submission https://juniperpublishers.com/online-submission.php 